\title{
Evaluation of the Effects of Inorganic and Organic Fertilizers and Activated Carbon on Bioremediation of Soil Contaminated with Weathered Crude Oil
}

\author{
AGARRY, SE \\ Biochemical and Bioenvironmental Engineering Laboratory, Department of Chemical Engineering, Ladoke Akintola University of \\ Technology, P. M. B. 4000, Ogbomoso, NIGERIA. \\ E-mail: sam_agarry@yahoo.com; seagarry@lautech.edu.ng; Tel: +2348055529705
}

\begin{abstract}
The objective of this study was designed to evaluate the effects of nutrients (inorganic NPK fertilizer and organic fertilizer) and adsorptive amendment agents (activated carbon) as well as their interactions on bioremediation of soil contaminated with Weathered Crude Oil (WECO). The organic fertilizer was made up of cattle dungs, pig dungs and poultry droppings mixtures. Box Behnken Design (BBD) of Response Surface Methodology (RSM) with three levels and three factors was used having inorganic NPK fertilizer (3 - $5 \mathrm{~g})$, activated carbon $(20-40 \mathrm{~g})$ and organic fertilizer $(30-50 \mathrm{~g})$ as independent variables and percentage WECO degradation as dependent variable (response) in a four weeks remediation period. Results of the study showed that WECO removal rate in soil is invariably dependent on the amount of nutrient and adsorptive agents. The optimum amount of nutrient and adsorptive amendment agents obtained to achieve a predicted maximum WECO removal of $66.24 \%$ are: inorganic NPK fertilizer, $4.19 \mathrm{~g}$; activated carbon, $35.42 \mathrm{~g}$ and organic fertilizer, $48.94 \mathrm{~g}$. At this predicted optimum amount, validation experiment revealed that $65.55 \%$ of WECO removal was achieved. Statistical analyses revealed the closeness of the experimental results to model predictions which thus show the reliability of the quadratic regression model. Therefore, organic and inorganic nutrients as well as adsorptive amendment alone and/or in combination enhances soil indigenous microbial density and activity which thereby accentuates petroleum hydrocarbons biodegradation and subsequently reduces the period of bioremediation and remediation cost.
\end{abstract}

DOI: https://dx.doi.org/10.4314/jasem.v22i4.27

Copyright: Copyright $\odot 2018$ Agarry. This is an open access article distributed under the Creative Commons Attribution License (CCL), which permits unrestricted use, distribution, and reproduction in any medium, provided the original work is properly cited.

Dates: Received: 06 April 2017; Revised: 27 February: 2018; Accepted: 23 March 2018

Keywords: Activated carbon; Box-Behnken design; Crude oil; Nutrients; Regression model

Bioremediation is an environmentally acceptable and cost-effective technology that exploits the diverse degradation abilities of microorganisms to efficiently convert complex chemical components of crude oil and other organic chemicals to harmless products by mineralization (Kao et al., 2008; Agarry et al., 2013a). Thus, there is the need to reduce the treatment time for bioremediation by accelerating the rate of degradation or recovery which could be referred to as enhanced bioremediation (Agarry et al., 2013a).

Enhanced bioremediation involves a wide variety of technologies (Chien et al., 2008) such as biosparging, biostimulation (which may involve the introduction of electron acceptors/electron donors into the ecosystem to stimulate autochthonous occurring microbial populations) and bioaugmentation (the addition of specific microorganisms) to enhance the biodegradation of the target contaminant or pollutant. In this regard, bioremediation technologies have been developed for soils and water using the addition of nutrients and microbes (Greenwood et al., 2008). The use of nutrient supplements such as inorganic fertilizer (Margesin et al., 2007; Agarry et al., 2013a), organic fertilizer in terms of animal dungs (Agarry et al., 2013b) and agricultural crop residues (Abioye et al., 2009; Agarry et al., 2013b) to biostimulate degraders in polluted matrices has been extensively studied. Nonetheless, the search for cost effective and environmentally friendly methods of petroleum hydrocarbon removal from contaminated environment still needs to be further investigated.

One of the various factors that have been identified which may limit the rate of crude petroleum degradation is the high toxicity of its chemical components to microbes and plants. This problem often restricts its use for highly contaminated soils (Vasilyeva et al., 2010, Meynet et al., 2012; Agarry et al., 2015). Activated or non-activated charcoals have been shown to reduce contaminant uptake from soil by plants (Vasilyeva et al., 2010; Jakob et al., 2012). However, information on the interaction effects of nutrients and adsorptive factors as well as its optimization required for enhanced bioremediation of ecosystem contaminated with petroleum hydrocarbons is still limited.

Therefore, the objective of this work was to study the bioremediation of soil contaminated with weathered crude oil via biostimulation and adsorptive remediation strategy using inorganic NPK fertilizer, organic fertilizer and commercial activated carbon as bioremediation agents. Box Behnken design was used to evaluate the influence and interactions of these bioremediation agents on the degradation rate and to optimize the agents for maximum crude oil removal. 


\section{MATERIALS AND METHODS}

Sample Collection: Escravos crude oil was obtained from an oil producing company located in Warri, Nigeria. Inorganic NPK fertilizer (20:10:10) was purchased from an agro-chemical store in Oleh, Nigeria. Cattle dung, pig dung and poultry droppings (animal wastes) used as organic fertilizer were obtained from a commercial farm in Benin, Nigeria. Commercial activated carbon was obtained from a chemical store in Benin, Nigeria. An un-impacted soil samples from local agricultural farms in Oleh town of Delta State, Nigeria, were collected from the surface layer of the vadose zone $15-30 \mathrm{~cm}$ below land surface.

Preparation of Sample: The crude oil prior to use was subjected to weathering by exposing it to the atmospheric sun condition for a period of 14 days with intermittent agitation and thereafter stored for subsequent utilization. The soil samples and the animal wastes were respectively sun-dried and homogenized, after which they were passed through a sieve of 2-mm pore size and then preserved in a polyethylene bag at prevailing room temperature.

Characterization of Sample: Soil samples and animal wastes were characterized for their physical, chemical and microbial parameters according to standard methods (APHA, 2005). The physical, chemical and microbial parameters that were characterized for are: total organic carbon, total nitrogen, total phosphorus, $\mathrm{pH}$, moisture content and total hydrocarbon utilizing bacteria (THUB). The method of characterization for each parameter has been presented in the previous study of Agarry (2017).
Microcosm Preparation and Bioremediation Experimentation: To optimize the range of experimentation for $2^{3}$ full-factorial Box-Behnken design, the following experiments were performed in plastic buckets maintained at ambient temperature. One kilogram soil samples were placed in plastic buckets (microcosm) and were spiked with weathered Escravos crude oil (WECO) to a level of $5 \% \mathrm{w} / \mathrm{w}$.

The crude oil-contaminated soil in each plastic bucket was amended with different amounts of inorganic NPK fertilizer $(2-5 \mathrm{~g})$, activated carbon $(10-40 \mathrm{~g})$ and organic fertilizer $(20-50 \mathrm{~g})$, respectively. Soil used as control (natural bioattenuation) was not amended with any of the fertilizer or activated carbon. In total, 16 microcosms were settled and incubated for 28 days. The content in all reactors were manually mixed once per week to enhance aeration, and was kept moist during the 28 days remediation period. Samples were withdrawn at one week (7 days) intervals for residual total petroleum hydrocarbon (TPH) analysis.

Experimental Design for Soil Bioremediation: BoxBehnken factorial experimental design was employed in this study and it had three independent variables viz., inorganic NPK (20:10:10) fertilizer, activated carbon and organic fertilizer. The three different independent variables was investigated at three levels of coded low level of -1 , medium coded level of 0 and high coded level of +1 with 17 standard runs of experiment as presented in Table 1.

Table 1: Experimental range and the levels of the variables

\begin{tabular}{lccc}
\hline Dependent factor & $\begin{array}{c}\text { Low Level } \\
(\mathbf{- ~ 1 )}\end{array}$ & $\begin{array}{c}\text { Medium Level } \\
(\mathbf{0})\end{array}$ & $\begin{array}{c}\text { High Level } \\
(+\mathbf{1})\end{array}$ \\
\hline Inorganic NPK Fertilizer (A), g & 3.0 & 4.0 & 5.0 \\
Activated carbon, g & 20 & 30 & 40 \\
Organic fertilizer, g & 30 & 40 & 50 \\
\hline
\end{tabular}

Table 2: Coded and uncoded full-factorial Box-Behnken design for the three independent variables

\begin{tabular}{ccccccc}
\hline Run & \multicolumn{2}{c}{ NPK Fertilizer } & \multicolumn{2}{c}{ Activated Carbon } & \multicolumn{2}{c}{ Organic Fertilizer } \\
& Code & Value $(\mathrm{g})$ & Code & Value $(\mathrm{g})$ & Code & Value $(\mathrm{g})$ \\
\hline 1 & -1 & 3 & -1 & 20 & 0 & 40 \\
2 & +1 & 5 & -1 & 20 & 0 & 40 \\
3 & -1 & 3 & +1 & 40 & 0 & 40 \\
4 & +1 & 5 & +1 & 40 & 0 & 40 \\
5 & -1 & 3 & 0 & 30 & -1 & 30 \\
6 & +1 & 5 & 0 & 30 & -1 & 30 \\
7 & -1 & 3 & 0 & 30 & +1 & 50 \\
8 & +1 & 5 & 0 & 30 & +1 & 50 \\
9 & 0 & 4 & -1 & 20 & -1 & 30 \\
10 & 0 & 4 & +1 & 40 & -1 & 30 \\
11 & 0 & 4 & -1 & 20 & +1 & 50 \\
12 & 0 & 4 & +1 & 40 & +1 & 50 \\
13 & 0 & 4 & 0 & 30 & 0 & 40 \\
14 & 0 & 4 & 0 & 30 & 0 & 40 \\
15 & 0 & 4 & 0 & 30 & 0 & 40 \\
16 & 0 & 4 & 0 & 30 & 0 & 40 \\
17 & 0 & 4 & 0 & 30 & 0 & 40 \\
$18($ Control $)$ & - & - & - & - & - & - \\
\hline
\end{tabular}


The levels were selected based on the above preliminary study results. The factors optimized were inorganic NPK fertilizer in the range of $3-5 \mathrm{~g}$, activated carbon $20-40 \mathrm{~g}$, and organic fertilizer $30-$ $50 \mathrm{~g}$, respectively. The percent TPH reduction was used as the dependent response variable. The efficiency of WECO biodegradation was assessed after 28 days. The coded and actual values of the amendment variables and levels utilized in the design of experiment is presented in Table 2. Crude oilcontaminated soil without biostimulation was also assayed as a control. The statistical software Design Expert 6.0.8, (Stat-Ease Inc., Minneapolis, USA) was used to evaluate the analysis of variance $(\mathrm{P}<0.05)$ to determine the significance of each term in the fitted equations and to estimate the goodness of fit in each case.

Estimation of Total Petroleum Hydrocarbon: The total petroleum hydrocarbon (TPH) estimation was carried out according to Mishra et al. (2001) and Agarry et al. (2013b), respectively. Ten grams of contaminated soil sample was taken from the soil microcosm and total petroleum hydrocarbon (TPH) was extracted from it with $50 \mathrm{ml}$ of hexane. The extract was then allowed to dry at room temperature by evaporation of the hexane solvent under a gentle nitrogen stream in a fume hood. After evaporation of the hexane solvent, the amount of residual TPH was determined by reading absorbance at $400 \mathrm{~nm}$ using visible range spectrophotometer (Model 6100 PYE UNICAM instruments England) and the TPH concentration was estimated from the standards curve, obtained from hexane extracts of fresh WECO at different concentrations.

\section{RESULTS AND DISCUSSION}

Soil and Animal Wastes Parameters: The values of soil and animal wastes parameters determined are presented in Table 3. The soil characterization revealed that the nutrient (NPK) requirements for an efficient biodegradation process are not fulfilled in the soil. These elements were then added in the form of inorganic and organic fertilizer to provide the proper nutrients required for the bioremediation process. The hydrocarbon degrading bacterial types identified in the soil samples were mainly Acinetobacter species, Bacillus species, Escherichia coli, Pseudomonas species, and Micrococcus species, Aspergillus species and Rhizopus species, while those species identified in the animal wastes were mainly Escherichia coli, Staphylococcus species, Salmonella species, Bacillus species, Lactobacillus species, Flavobacterium species, Methanobacterium species and Pseudomonas species.

\begin{tabular}{lllll}
\multicolumn{4}{c}{ Table 3: Physical, chemical and microbiological properties of soil and animal wastes } \\
\hline Parameter & Soil & Cattle dung & Pig dung & $\begin{array}{l}\text { Poultry } \\
\text { droppings }\end{array}$ \\
\hline Organic Carbon (\%) & $2.25 \pm 0.02$ & $27.6 \pm 0.03$ & $29.4 \pm 0.01$ & $25.7 \pm 0.02$ \\
Total Nitrogen (\%) & $1.47 \pm 0.03$ & $2.80 \pm 0.01$ & $3.67 \pm 0.02$ & $3.10 \pm 0.02$ \\
Carbon: Nitrogen & $1: 1.53$ & $10: 1$ & $8: 1$ & $8.3: 1$ \\
Phosphorus (\%) & $0.10 \pm 0.01$ & $0.19 \pm 0.02$ & $0.25 \pm 0.01$ & $0.39 \pm 0.02$ \\
pH & $7 \pm 0.2$ & $7.7 \pm 0.1$ & $7.9 \pm 0.1$ & $7.3 \pm 0.2$ \\
Moisture (\%) & $12.4 \pm 0.1$ & $7.9 \pm 0.2$ & $8.1 \pm 0.1$ & $7.0 \pm 0.2$ \\
THUB (cfu/g) & $0.1 \pm 0.8 \times 10^{5}$ & $0.2 \pm 3.7 \times 10^{6}$ & $0.2 \pm 4.1 \times 10^{6}$ & $0.3 \pm 2.9 \times 10^{6}$ \\
\hline
\end{tabular}

Natural Bioattenuation and Enhanced Bioremediation: After the 17 runs of the Box-Behnken design (BBD) and one control were performed, the experimental results obtained are presented in Table 4. Table 4 shows that on day 28 ( $4^{\text {th }}$ week), TPH content in WECO had decreased in all the plastic reactors (microcosms). In control, natural biodegradation (natural bioattenuation) removed $26.40 \%$ TPH. Mohajeri et al. (2010) and Agarry and Ogunleye (2012b) showed that natural attenuation removed 912.6 and 44.78 per cent of crude oil after 60 and 42 days remediation periods, respectively. Bioremediation efficiency is a function of the microbial viability in the natural ecological system (Joo et al., 2008) and their viability is also dependent on some factors such as nutrient availability. As presented in Table 4, the reduction in TPH content of soil microcosms containing amendments was much higher in the same remediation period.
These results indicate that the addition of nutrients and/or adsorptive agents increased the rate of TPH reduction (biodegradation). A considerable decrease in TPH was observed in runs 11 to 17 , with a relatively high amount of inorganic NPK fertilizer, activated carbon and organic fertilizer. Agarry et al. (2012) in their study of enhanced bioremediation of soil contaminated with kerosene have reported that natural attenuation removed $38.5 \%$ of kerosene oil after 42 day remediation period, and when the soil was amended with NPK fertilizer, hydrogen peroxide, and Tween $80,77.89 \%$ of the kerosene oil was removed. In addition, Agarry and Ogunleye (2012a) in their study of enhanced bioremediation of soil artificially contaminated with spent engine oil have shown that natural attenuation removed $28.8 \%$ of spent engine oil after 42-day remediation period, and when the soil was amended with NPK fertilizer, Tween 80 and pig dung, $66.47 \%$ of the spent engine oil was removed. Furthermore, Agarry and Ogunleye (2012b) in their 
study of enhanced bioremediation of soil artificially contaminated with Bonny light crude oil have also shown that natural attenuation removed $44.78 \%$ of crude oil after 42-day remediation period, and when the soil was amended with NPK fertilizer, Tween 80 and mixed culture, $83.79 \%$ of the crude oil was removed. In comparing this study with the results of Agarry et al. (2012), Agarry and Ogunleye (2012a) and Agarry and Ogunleye (2012b); it could be seen that the percentage of petroleum hydrocarbon removal was lower in both the natural attenuation and biostimulation or amendment treatments. This may be due to the difference in the remediation period where 28 days was used in this study as compared to 42 days used by Agarry et al. (2012), Agarry and Ogunleye (2012a) and Agarry and Ogunleye (2012b), respectively as well as on the heterogeneity of the soil. This observation indicates that bioremediation is time dependent.

\begin{tabular}{ccc}
\multicolumn{3}{c}{ Table 4: Results for WECO removal from contaminated soil } \\
\hline Experimental & \multicolumn{2}{c}{ Percentage of TPH Reduction } \\
\cline { 2 - 3 } Run & Observed Value & Predicted Value \\
\hline 1 & 48 & 47.13 \\
2 & 46 & 46.63 \\
3 & 49 & 48.38 \\
4 & 54 & 54.88 \\
5 & 48 & 49.38 \\
6 & 50 & 49.88 \\
7 & 52 & 52.13 \\
8 & 59 & 57.63 \\
9 & 56 & 55.50 \\
10 & 58 & 57.75 \\
11 & 57 & 65.50 \\
12 & 65 & 63.00 \\
13 & 63 & 63.00 \\
14 & 63 & 63.00 \\
15 & 63 & 63.00 \\
16 & 63 & 63.00 \\
17 & 63 & 63.00 \\
18 (Control) & - & 26.40 \\
\hline
\end{tabular}

At 5\% (w/w) WECO concentrations, run numbers 2 and 4 , and runs number 11 and 12 had same remediation condition with different dosage of activated carbon; results shows that addition of activated carbon can enhance crude oil removal. Similar observations have been reported for the use of activated carbon in the remediation of environment contaminated with herbicide propanil (3',4'dichloropropionanilide) in the Krasnodar region of Russia, 3,4-dichloroaniline, polychlorinated biphenyls (PCB), 2,4,6-trinitrotoluene (TNT) (Vasilyeva et al., 2010), anthracene (Owabor and Aluyor, 2008), diesel fuel (Semenyuk et al., 2014) and crude oil (Agarry et al., 2015). Effect of different amount of organic fertilizer (cattle dung + pig dung+ poultry droppings) on TPH biodegradation were investigated at the same condition of inorganic NPK fertilizer and activated carbon (run numbers 6 and 8, and run numbers 10 and 12) and the results showed that addition of organic fertilizer (cattle dung + pig dung + poultry droppings) can enhance the bioremediation process of soil contaminated with crude oil. This is in agreement with the observations of Ibiene et al. (2011), Nduka et al. (2012), Chikere et al. (2012) and Obiakalaije et al. (2015) who respectively used poultry droppings and/or cow dung as organic fertilizer (biostimulation agents) in the remediation of petroleum hydrocarbon contaminated environment. Agarry et al. (2010) and Agarry et al. (2013b) had in their previous studies also reported the enhancement of bioremediation in soil contaminated with petroleum hydrocarbons using cow dung, pig dung, poultry dung as well as the mixture of cow dung and pig dung, respectively.

In addition, run numbers 3 and 4; and run numbers 7 and 8 had same condition with different amount of inorganic NPK fertilizer; the results indicate that extra addition of inorganic fertilizer extensively improved crude oil biodegradation from 49 to $54 \%$ and from 52 to $59 \%$, respectively. Similar observations have been reported (Chorom et al., 2010; Chikere et al., 2012; Agarry and Ogunleye, 2012a, 2012b). Thus, the observed results seems to suggest that high nutrient amendment dosage can accentuate the rate of initial petroleum hydrocarbon biodegradation and then reduce the remediation period of environment contaminated with crude oil. The accelerating effect of amendment is stronger when nutrient availability is a limiting factor in the biodegradation of oil (Mohajeri et al., 2010; Agarry and Ogunleye, 2012a).

Quadratic Regression Model and Analysis of Statistics: The biodegradation data were fitted to a multiple regression model as given in Eq. (1) that has both linear, quadratic and interaction terms (Mohajeri et al., 2010). Where $\alpha_{o} ; \alpha_{1}, \alpha_{2}, \alpha_{3} ; \alpha_{11}, \alpha_{22}, \alpha_{33}$ ; and $\alpha_{12}, \alpha_{13}, \alpha_{23}$ are the corresponding centre point value of the fixed response, linear, quadratic and interaction coefficients regression terms while A, B and $\mathrm{C}$ are the respective independent levels of amendment variables.

The quadratic regression equation obtained after analysis of variance (ANOVA) gives the level of TPH reduction (crude oil removal) as a function of the different amendment factors: inorganic NPK fertilizer, activated carbon, and organic fertilizer. The statistical experimental results obtained were analyzed with regard to the coded design matrix. The second-order quadratic regression model equation revealed that the rate of WECO degradation was a function of the applied variables. Each one of the regression terms irrespective of whether they are significant or not were included in the obtained Eq. (2):

$$
Z=\alpha_{o}+\alpha_{1} A+\alpha_{2} B+\alpha_{3} C+\alpha_{11} A^{2}+\alpha_{22} B^{2}+\alpha_{33} C^{2}+\alpha_{12} A B+\alpha_{13} A C+\alpha_{23} B C
$$


$Z=63+1.50 A+2.38 B+2.63 C-10.25 A^{2}-3.50 B^{2}-0.50 C^{2}+1.75 A B+1.25 A C+1.50 B C$

Table 5: ANOVA for the quadratic response surface model fitting to the WECO biodegradation data

\begin{tabular}{llclll}
\hline Source & Sum of squares & $\mathbf{D F}$ & Mean square & $\mathbf{F}_{\text {-value }}$ & $\mathbf{P}_{\text {-value }}$ \\
\hline Model & 663.78 & 9 & 73.75 & 66.62 & $<0.0001$ \\
& & & & & \\
Residual (error) & 7.75 & 7 & 1.11 & & - \\
Lack of Fit & 7.75 & 3 & 2.58 & - & \\
Pure Error & 0.00 & 4 & 0.000 & & \\
Correlation Total & 671.53 & 16 & & & \\
\hline
\end{tabular}

The coefficient of the model (parameter estimation) and the corresponding P-values are presented in Table 6.

Table 6: Coefficient of the model for WECO biodegradation

\begin{tabular}{lccccc}
\hline Variable & Coefficient Estimate & Standard Error & $\mathbf{F}_{\text {-value }}$ & $\mathbf{P}_{\text {-value }}$ & Remarks \\
\hline$\alpha_{o}$ & 63 & 0.47 & 66.62 & $<0.0001$ & Significant \\
$\alpha_{1}$ & 1.50 & 0.37 & 16.26 & 0.0050 & Significant \\
$\alpha_{2}$ & 2.38 & 0.37 & 40.76 & 0.0004 & Significant \\
$\alpha_{3}$ & 2.63 & 0.37 & 49.79 & 0.0002 & Significant \\
$\alpha_{11}$ & -10.25 & 0.51 & 399.56 & $<0.0001$ & Significant \\
$\alpha_{22}$ & -3.50 & 0.51 & 46.59 & 0.0002 & Significant \\
$\alpha_{33}$ & -0.50 & 0.51 & 0.95 & 0.3620 & Not Significant \\
$\alpha_{12}$ & 1.75 & 0.53 & 11.06 & 0.0127 & Significant \\
$\alpha_{13}$ & 1.25 & 0.53 & 5.65 & 0.0492 & Significant \\
$\alpha_{23}$ & 1.50 & 0.53 & 8.13 & 0.0246 & Significant \\
\hline
\end{tabular}

Where A is amount of inorganic NPK fertilizer, B is dosage (or amount) of activated carbon; $\mathrm{C}$ is amount of organic fertilizer. To test the model fit, the quadratic regression equation and coefficient of determination $\left(\mathrm{R}^{2}\right)$ were evaluated (Table 5). The Fischer test (F-test) and probability values (P-values) were used to determine the significance of each equation coefficient. The model F-value of 66.62 implies the model is significant $(P<0.05)$ at the $95 \%$ confidence interval.

The low $\mathrm{P}$-value $(<0.0001)$ indicates that the model is significant. The $\mathrm{R}^{2}$ value of 0.9885 obtained showed that there is a very good agreement (i.e. high degree of correlation) between the observed TPH reduction value and predicted TPH reduction values. In addition, the correlation coefficient (R) value of 0.9942 obtained reveals that $99.42 \%$ of the variance could be due to the amendment variables and thus indicates that the model is highly significant. The Predicted $\mathrm{R}^{2}$ value of 0.8153 is found to be in a reasonable concordance with the Adjusted $\mathrm{R}^{2}$ value of 0.9736 . Adequate Precision measures the signal to noise ratio. A ratio greater than 4 is desirable. In this study, a ratio of 23.389 was obtained which reveals an adequate signal. This model can be used to navigate the design space. A model is generally considered to be reproducible if its coefficient of variation $(\mathrm{CV})$ is not greater than $10 \%$. In order words, the low CV value of $1.87 \%$ obtained in this study revealed that the experiment was highly precise and reliable.

The significance of regression coefficients was considered, ignoring those with an insignificant effect on the response at a significance level of $95 \%$. The Pvalues of the regression coefficients suggest that among the test factors, linear, quadratic and interaction effects of inorganic NPK fertilizer, activated carbon and organic fertilizer are highly significant. The insignificant effects (factors and interactions) with Pvalues higher than 0.05 , were ignored. In this study, $\mathrm{A}$, $\mathrm{B}, \mathrm{C}, \mathrm{A}^{2}, \mathrm{~B}^{2}, \mathrm{AB}, \mathrm{AC}$ and $\mathrm{BC}$ are significant model terms.

Therefore, the statistical analysis of all the experimental data revealed that inorganic NPK fertilizer, activated carbon and organic fertilizer had a significant effect on TPH reduction (crude oil removal) during the study. Moreover, it is observed that organic fertilizer exerted more pronounced linear effect (higher coefficient values) on TPH reduction (crude oil removal). That is, TPH reduction (crude oil removal) was mostly and positively influenced by organic fertilizer followed by activated carbon and inorganic NPK fertilizer. The strong influence of crop residues and animal dungs than NPK fertilizer as nutrients on petroleum hydrocarbons removal has been clearly shown before in the previous works of Agarry et al. (2013). The individual amendment variables had a negative but significant quadratic effect on the TPH degradation. 
Effects of Amendment Factors Interaction on Crude Oil Biodegradation: Table 6 showed that TPH reduction (crude oil removal) was influenced positively by interaction of inorganic NPK fertilizer (A) and activated carbon (B); inorganic NPK fertilizer (A) and organic fertilizer (C); and activated carbon (B) and organic fertilizer $(\mathrm{C})$, respectively. The interaction effect of inorganic NPK fertilizer and activated carbon exerted more pronounced positive influence (due to higher coefficient) on TPH reduction or biodegradation (crude oil removal) than the linear effect of inorganic NPK fertilizer. The graphical representation of the response presented in Fig. 1to Fig. 3 helped to visualize the effect of inorganic NPK fertilizer (A), activated carbon (B) and organic fertilizer (C) on percent TPH reduction (crude oil removal). The interaction effect of inorganic NPK fertilizer and activated carbon on TPH biodegradation (crude oil bioremediation) is illustrated in Fig. 1.

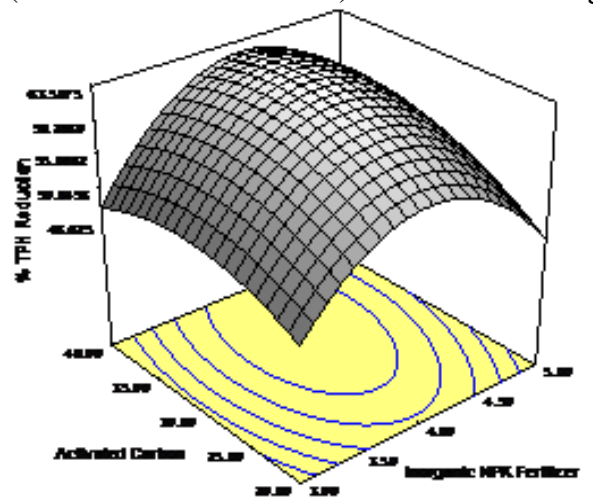

Fig. 1: Three dimensional (3D) Response surface plots indicating interaction effects of inorganic NPK fertilizer and activated carbon

It is seen that a higher percentage of TPH reduction was obtained at a higher dosage of activated carbon and relatively high amount of inorganic NPK fertilizer. This 3D response surface plot explains that both activated carbon and inorganic NPK fertilizer has direct impact on crude oil removal as the individual coefficient of both activated carbon and inorganic NPK fertilizer is positive and their interaction effect is positive. A positive interactive effect of NPK fertilizer and Tween 80 on the biodegradation of petroleum hydrocarbon in spent engine oil, Bonny light crude oil and kerosene has been reported (Agarry and Ogunleye, 2012a; Agarry and Ogunleye, 2012b; Agarry et al., 2012). However, the direct impact of activated carbon is more than that of inorganic NPK fertilizer as the individual coefficient value is higher for activated carbon (2.38) than for inorganic NPK fertilizer (1.50). The maximum TPH reduction or crude oil biodegradation $(63.51 \%)$ was achieved with about 30 $\mathrm{g}$ of activated carbon and $4 \mathrm{~g}$ of inorganic NPK fertilizer. Further increase in the amount of inorganic NPK fertilizer ( $>4.0 \mathrm{~g}$ ), a significant decrease in the TPH biodegradation yields occurred. This suggests that at a fixed amount of organic fertilizer, the amount of initial NPK fertilizer can be decreased and that of activated carbon has to be increased for higher percentage reduction in TPH yield. The positive interactive effect of inorganic NPK fertilizer and activated carbon on petroleum hydrocarbon degradation in crude oil is relatively higher (due to high coefficient value of 1.75) though with lower maximum TPH yield $(63.51 \%)$ as compared to the interaction effect of NPK fertilizer and Tween 80 on the biodegradation of petroleum hydrocarbon in spent engine oil (coefficient value of 0.47), Bonny light crude oil (coefficient value of 0.71 ) and kerosene oil (coefficient value of 0.27 ), with a maximum degradation yield of $74.95 \%, 84.79 \%$ and $66.85 \%$ as presented in the previous work of Agarry and Ogunleye (2012a), Agarry and Ogunleye (2012b), and Agarry et al. (2012), where they respectively used BoxBehnken design of experiments to study the interaction effects of NPK fertilizer, Tween 80, hydrogen peroxide, mixed culture and pig dung. Though the maximum biodegradation yield may be low due to lesser remediation time, however, the comparisons imply that the activated carbon can perform the purpose of acting as an adsorbentfor the crude oil as well as improves the aeration process for the soil microorganisms as the hydrogen peroxide serves to do (Agarry and Ogunleye, 2012a).

Fig. 2 shows the three dimensional (3D) response surface plot of the interaction effect between inorganic NPK fertilizer and organic fertilizer.

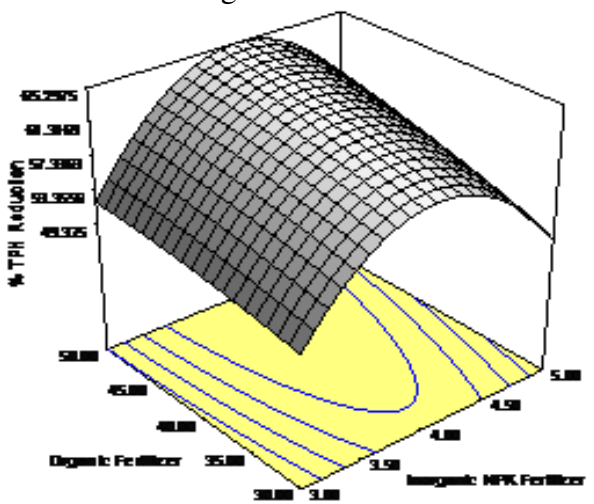

Fig. 2: Three dimensional (3D) Response surface plots indicating interaction effects of inorganic NPK fertilizer and organic fertilizer

The plot shows that higher percentage of TPH reduction was achieved with increase in the amount of inorganic NPK fertilizer and organic fertilizer. This three dimensional plot indicates that both initial NPK fertilizer and organic fertilizer has direct influence on TPH biodegradation as the individual coefficient of both inorganic NPK fertilizer and organic fertilizer is positive and their interaction effect is positive. The positive influence of the interaction effect of NPK fertilizer and mixed culture, interaction effect of NPK fertilizer and pig manure and interaction effect of NPK fertilizer and hydrogen peroxide at a fixed amount of Tween 80 (nonionic surfactant) has been reported by Agarry and Ogunleye (2012b), Agarry and Ogunleye 
(2012a), and Agarry et al. (2012) in the enhanced bioremediation of soil contaminated with Bonny light crude oil, spent engine oil and kerosene oil, respectively. Nevertheless, the direct impact of organic fertilizer is more than that of inorganic NPK fertilizer as the main coefficient value is higher for organic fertilizer (2.63) than for inorganic NPK fertilizer (1.50). When $30 \mathrm{~g}$ of activated carbon was used, the highest percentage of TPH reduction $(65.30 \%)$ was obtained with $4 \mathrm{~g}$ of inorganic NPK fertilizer and $40 \mathrm{~g}$ of organic fertilizer. Further increase in the amount of inorganic NPK fertilizer ( $>4.0 \mathrm{~g})$, a significant decrease in the percentage of TPH biodegradation yields occurred.

This suggests that at a fixed amount of activated carbon, the amount of initial NPK fertilizer can be decreased and that of organic fertilizer has to be increased for higher percentage reduction in TPH yield.The positive influence of inorganic NPK fertilizer and organic fertilizer interaction on petroleum hydrocarbon degradation in crude oil is relatively high (due to high coefficient value of 1.25 ) though with lower maximum TPH yield $(65.30 \%)$ as compared to the interaction effect of NPK fertilizer and hydrogen peroxide (coefficient value of 1.02), interaction effect of NPK fertilizer and mixed culture (coefficient value of 1.50), and interaction effect of NPK fertilizer and pig manure (coefficient value of 1.96)on the biodegradation of petroleum hydrocarbon in kerosene oil, Bonny light crude oil, and spent engine oil with a maximum degradation yield of $75.07 \%$, $84.97 \%$ and $67.34 \%$ at a fixed concentration of Tween 80 as presented in the previous work of Agarry et al. (2012), Agarryand Ogunleye (2012a) and Agarry and Ogunleye (2012b), where they respectively used BoxBehnken design of experiments to study the interaction effects of NPK fertilizer, Tween 80, hydrogen peroxide, mixed culture and pig dung.

Though the maximum biodegradation yield may be low due to the earlier suggested reasons, however, the comparisons imply that the organic fertilizer can perform the dual purpose of providing nutrient (biostimulation) as well as microorganisms (bioaugmentation) for the soil just as the mixed culture serves and also improves the aeration process for the soil microorganisms as the hydrogen peroxide serves to do (Agarry and Ogunleye, 2012a).

Finally, the interactive effect between activated carbon and organic fertilizer is as shown in the three dimensional response surface plot of Fig. 3. This 3D plot demonstrates that both activated carbon and organic fertilizer have positive mutual impact on the crude oil removal process. At a fixed amount of inorganic NPK fertilizer, it was observed that increase in activated carbon and organic fertilizer resulted in higher percentage of TPH reduction. The maximum reduction in TPH (66.19\%) was obtained with $30 \mathrm{~g}$ of activated carbon and $40 \mathrm{~g}$ of organic fertilizer and this interactivevariables demonstrated the most suitable performance in the TPH degradation.

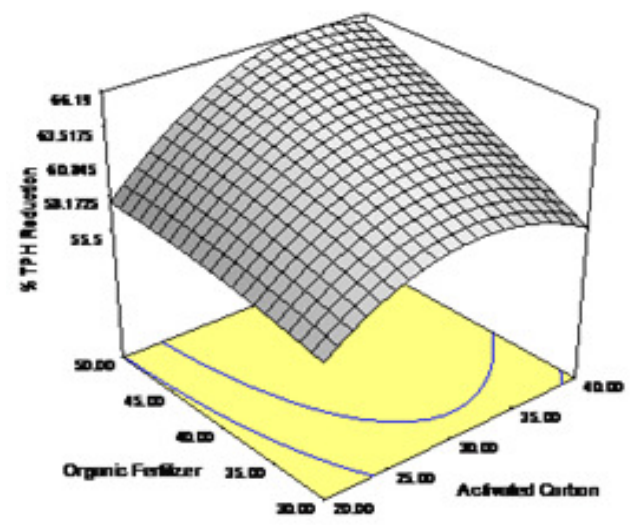

Fig. 3: Three dimensional (3D) Response surface plots indicating interaction effects of activated carbon and organic fertilizer

Perturbation Plot: The effect of each variable was assessed graphically using the perturbation or factor plot as shown in Fig. 4.

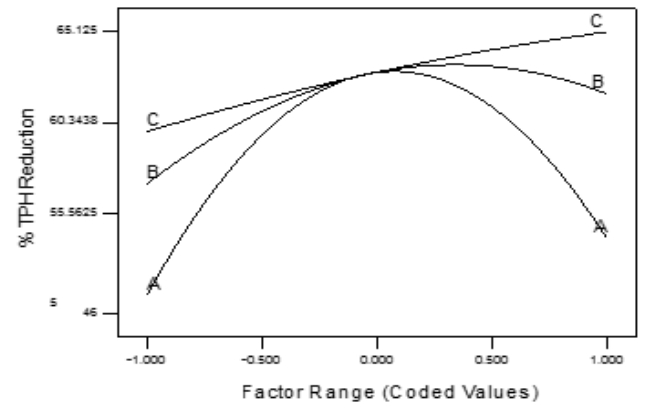

Fig. 4: Perturbation plot showing the impact of individual variableon TPH reduction

From the perturbation plot of Fig 4, it is observed that the individual variables of NPK fertilizer, organic fertilizer and activated carbonutilized had its majorimpact on TPH degradation by the soil autochthonous microbialpopulation. Gradual increase in the amount of NPK fertilizer and activated carbon from low level (coded value -1 ) to a higher level (coded value +1) resulted in both increase and decrease of crude oil biodegradation (TPH reduction). While progressive increase in the amount of organic fertilizer from low level (coded value -1 ) to a higher level (coded value +1 ) resulted in the increase of percentage TPH reduction.Furthermore, it was to be observed that the TPH degradation or reduction changed in a wide range with inorganic NPK fertilizer used over the range of low coded level of -1 (actual value of $3 \mathrm{~g}$ ) through the medium level (0) to high coded level of +1 (actual value of $5 \mathrm{~g}$ ). This was also the case for activated carbon; however, for organic fertilizer it did not change over a wide range. This clearly revealed that keeping organic fertilizer at the optimum level, a change in inorganic NPK fertilizer 
and activated carbon will affect the process of bioremediation more severely than done otherwise.

Numerical Optimization of Crude Oil Biodegradationand Experimental Validation

To determine the optimal workable conditions of the amendment variables in achieving an optimum crude oil degradation, the numerical optimization tool of Design Expert was utilized. This optimization tool is based on the function of desirability. In order to provide an ideal case for bioremediation, the goal for inorganic NPK fertilizer, activated carbon and organic fertilizer was set in range based upon the requirements of the crude oil bioremediation and percentage of TPH reduction was set on maximize. The predicted optimum (uncoded) values of inorganic NPK fertilizer, activated carbon and organic fertilizer were found to be $4.19 \mathrm{~g}, 35.42 \mathrm{~g}$ and $48.94 \mathrm{~g}$, respectively, to achieve $66.24 \%$ maximum TPH reduction (crude oil biodegradation); while desirability was 1.000 for the experiment (Fig. 5).

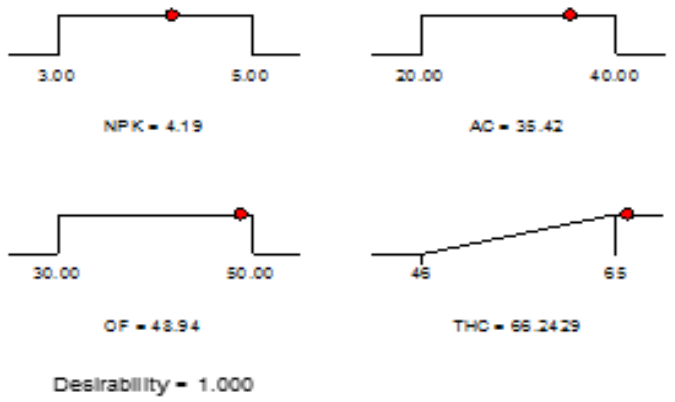

Fig. 5: Plot of desirability for optimization of crude oil biodegradation

In addition, validation experiment was performed to determine the optimum TPH reduction (crude oil biodegradation) when the amendment factors were set at the above established predicted optimum levels. Errors between predicted and actual values were calculated according to Eq. (3) (Mohajeri et al., 2010; Agarry and Ogunleye, 2012a).

$$
\text { Error }=\frac{\text { actualvalu }- \text { predictedvalue }}{\text { actualvalue }} \times 100
$$

In the optimized condition for initial WECO of $5 \%$ (w/w) concentration, $65.55 \% \mathrm{TPH}$ reduction was achieved. The percentage error between the predicted and actual values was found to be -0.011 . The results indicated that there was no significant difference between the predicted and actual values obtained from validation experiment. Sixty-eight (68) percent and fifty-eight (58) percent petroleum hydrocarbon removal from contaminated environment have been reported by Nievas et al. (2006) and Thavasi et al. (2006), respectively.

Conclusions: The variations in weathered Escravoscrude oil biodegradation pattern with respect to the amount of inorganic NPK fertilizer, activated carbon and organic fertilizer contents were observed to be very significant. The results indicated that biostimulation (using nutrient in the form of inorganic NPK fertilizer and organic fertilizer as well as activated carbon) of crude oil contaminated soil resulted in the enhancement of petroleum hydrocarbon biodegradation. RSM is a reliable and powerful tool for modeling and optimization of crude oil bioremediation processes; in the optimum conditions petroleum hydrocarbons were removed up to $65.55 \%$ in soil.

\section{REFERENCE}

Abioye, PO; Abdul Aziz, A; Agamuthu, P. (2009). Enhanced biodegradation of used engine oil in soil amended with organic wastes. Water Air Soil Poll. 209:173 - 179.

Agarry, SE; Owabor, CN; Yusuf, RO (2010). Bioremediation of soil artificially contaminated with petroleum hydrocarbon mixtures: Evaluation of the use of animal manure and chemical fertilizer. Bioremediation J.14 (4):189 - 195.

Agarry, SE; Ogunleye, OO (2012a). Box-behnken designs application to study enhanced bioremediation of soil artificially contaminated with spent engine oil using biostimulation strategy. Int. J. Energy and Environ. Eng.3:31-34.

Agarry, SE; Ogunleye, OO (2012b). Factorial designs application to study enhanced bioremediation of soil artificially contaminated with weathered Bonny light crude oil through biostimulation and bioaugmentation strategy. J. Environ. Protection3:748-759.

Agarry, SE; Aremu, MO; Aworanti, OA (2013a). Kinetic modelling and half-life study on bioremediation of soil co-contaminated with lubricating motor oil and lead using different bioremediation strategies. Soil and Sediment Contam. - An Int. J. 22 (7):800 - 816.

Agarry, SE; Aremu, MO; Aworanti, OA (2013b). Kinetic modelling and half-life study on enhanced soil bioremediation of bonny light crude oil amended with crop and animal-derived organic wastes. J. Pet Environ. Biotechnol. 4: 137.

Agarry, SE; Owabor, CN; Yusuf, RO (2012). Enhanced bioremediation of soil artificially contaminated with kerosene: Optimization of biostimulationagents through statistical experimental design. J. Pet Environ. Biotechnol. 3:120.

Agarry, SE; Oghenejoboh, KM; Solomon, BO (2015). Kinetic modelling and half- life study of adsorptive bioremediation of soil artificially contaminated with bonny light crude oil.J. Ecol.Eng.16 (3):1-13.

APHA (2005). Standard Methods for Examination of water and wastewater. American Public Health Association, Washington D.C.

Chien, HY; Kao, CM; Jou, CJ; Yang, PY; Huang, CC (2008). Application of enhanced bioremediation to clean up diesel-oil contaminated soils: Laboratory 
microcosm study. J. Biotechnol.136:S682.

Chikere, CB; Chikere, BO; Okpokwasili, GC (2012). Bioreactor-based bioremediation of hydrocarbonpolluted Niger Delta marine sediment, Nigeria. 3 Biotech2:53-66.

Chorom, M; Sharif, HS; Mutamedi, H (2010). Bioremediation of a crude oil-polluted soil by application of fertilizers. Iran J. Environ. Health Sci. Eng.7 (4):319-326.

Greenwood, PF; Wibrow, S; George, SJ; Tibbett, M (2008). Sequential hydrocarbon biodegradation in a soil from arid coastal Australia, treated with oil under laboratory controlled conditions. Org. Geochem. 39:1336 - 1346.

Ibiene, AA; Orji, FA; Ezidi, CO; Ngwobia, CL (2011). Bioremediation of hydrocarbon contaminated soil in the Niger Delta using spent mushroom compost and other organic wastes. Nig. J. Agric. Food and Environ. 7(3):1-7.

Jakob, L; Hartnik, T; Henriksen, T; Elmquist, M; Brändli, RC; Hale, SE; Cornelissen, G. (2012). PAHsequestration capacity of granular and powder activated carbon amendments in soil, and their effects on earthworms and plants. Chemosphere 88:699-705.

Joo, H; Ndegwa, PM; Shoda, M; Phae, C (2008). Bioremediation of oil-contaminated soil using Candida catenulata and food waste. Environ. Pollute. 156:891 896.

Kao, CM; Chen, CY; Chen, SC; Chien, HY; Chen, YL (2008). Application of in situ biosparging to remediate a petroleum hydrocarbon spill site: Field and microbial evaluation. Chemosphere 70: 1492-1499.

Margesin, R; Hammerle, M; Tscherko, D (2007). Microbial activity and community composition during bioremediation of diesel-oil-contaminated soil: Effects of hydrocarbon concentration, fertilizers, and incubation time. Microbiol Ecol. 53:259 - 269.

Meynet, P; Hale, SE; Davenport, RJ; Cornelissen, G; Breedveld, GD; Werner, D (2012). Effect of activated carbon amendment on bacterial community structure and functions in a PAH impacted urban soil. Environ. Sci. Technol. 46:5057-5066.

Mohajeri, L; Abdul Aziz, H; Isa, MH; Zahed, MA (2010). A statistical experiment design approach for optimizing biodegradation of weathered crude oil in coastal sediments. Bioresour. Technol. 101:893-900.

Nduka, JK; Umeh, LN; Okerulu, IO; Umedum, LN; Okoye, HN (2012). Utilization of different microbes in bioremediation of hydrocarbon contaminated soils stimulated with inorganic and organic fertilizers. J. Pet Environ. Biotechnol. 3:116.

Nievas, ML; Commendatore, MG; Olivera, NL;Esteves, JL; Bucalá, V (2006). Biodegradation of bilge waste from Patagonia with an indigenous microbial community. Bioresour. Technol. 97:2280-2290.

Obiakalaije, UM; Makinde, OA; Amakoromo, ER (2015). Bioremediation of Crude Oil Polluted Soil Using Animal Waste. Int. J. Environ. Bioremed. Biodegrad. 3 (3):79-85.

Owabor, CN; Aluyor, EO (2008). Application of adsorbent as a novel technique during biodegradation of a polycyclic aromatic hydrocarbon (anthracene). Afri. J. Biotechnol.7 (18):3321-3325.

Semenyuk, NN; Yatsenko, VS; Strijakova, ER; Filonov, AE; Petrikov, KV; Zavgorodnyaya, YA; Vasilyeva, GK (2014). Effect of activated charcoal on bioremediation of diesel fuel-contaminated soil. Microbiol. 83 (5):589598.

Thavasi, R., Jayalakshmi, S., Balasubramanian, T., and Banat, I. M. (2006). Biodegradation of Crude Oil by Nitrogen Fixing Marine Bacteria Azotobacterchroococcwn. Res. J. Microbiol., Vol. 1 (1), pp. 401- 408.

Vasilyeva, G. K., Strijakova, E. R., Nikolaeva, S. N., Lebedev, A. T., and Shea, P. J. (2010). Dynamics of PCB removal and detoxification in historically contaminated soils amended with activated carbon. Environ. Pollut. 158:770 -777. 